\title{
Workplace Violence Against Healthcare Professionals in Thai Tertiary Hospitals
}

\author{
Sophida Kueanongkhun \\ Mahidol University \\ Siriwan Grisurapong \\ Mahidol University \\ Kitirat Techatraisak \\ Mahidol University \\ Thomas E. Guadamuz ( $\nabla$ tguadamu@hotmail.com ) \\ Mahidol University
}

\section{Research Article \\ Keywords: Workplace violence, Healthcare worker, Tertiary Hospital violence, Thailand}

Posted Date: September 28th, 2021

DOI: https://doi.org/10.21203/rs.3.rs-910003/v1

License: @) (i) This work is licensed under a Creative Commons Attribution 4.0 International License. Read Full License 


\section{Abstract}

Background: Thailand lacks evidence of the current prevalence of workplace violence (WPV) at tertiary hospitals. This study aimed to examine the prevalence of, perpetrators of, and factors associated with WPV against healthcare workers in excellent tertiary hospitals in Thailand.

Methods: This was a mixed-methods study. A questionnaire was individually administered by an interviewer to 220 healthcare workers using a tablet with an online platforms, and the completion rate was 100\%. The study was conducted from July 2018 to March 2019. Pearson's chisquare test was used to examine the variables related to any violence according to individual and work data. Odds ratios with $95 \%$ confidence intervals were used to assess risk factors for exposure to violence using a logistic regression model. Thirty participants provided additional qualitative data that were used for thematic analysis.

Results: The findings revealed that in the past 12 months, $63.6 \%$ of the participants experienced violence at their workplaces. The most common type of violence reported was verbal violence $(56.4 \%)$, followed by physical violence $(24.1 \%)$, bullying (16.4\%), sexual harassment $(4.1 \%)$, and racial harassment (3.6\%). Multivariable logistic regression revealed that the correlates of violence at hospitals included being male $(O R=4.28$, $95 \% \mathrm{Cl} 1.50-12.19)$, working in an outpatient department $(\mathrm{OR}=2.55,95 \% \mathrm{Cl} 1.42-4.58)$, and having direct contact with clients $(\mathrm{OR}=3.12,95 \%$ Cl 1.25-7.73). The qualitative data revealed 5 major themes.

Conclusion: There is a high prevalence of violence against all healthcare workers at excellent tertiary hospitals in Thailand. Policymakers need to be aware of the roots and risk factors for all types of WPV. The results could also contribute to the development of appropriate policies, interventions for conflicts based on intergenerational gaps, reporting, investigation processes, preventive measures, and zero-tolerance protocols for all healthcare workers.

\section{Background}

Violence against healthcare workers is not novel but is a phenomenon that is known worldwide and observed in all areas and hospital careers with serious consequences (1-4). Violence has the ability to threaten or damage all systems (5-7), such as physical well-being, psychological well-being, job performance, satisfaction, burnout, and quality of life, among staff (8-11). Violence exists in many forms and dimensions (1214). Previous international studies reported high prevalences of workplace violence (WPV) in various Asian countries, i.e., $44.6-99.5 \%$, which varied depending on the different types and contexts of violence (15-18). Although hospital violence has been gaining increasing attention for many decades worldwide, little international evidence has been published on Thailand and Southeast Asia, including little evidence on the reporting of violent events $(19,20)$. Moreover, there is a lack of evidence on the current prevalence of hospital violence in Thailand. Many factors related to hospital violence have been revealed, including demographic factors of participants $(21,22)$, perpetrator attributes $(23)$, and work characteristics $(24,25)$. In particular, previous research has found that factors such as the type, size, and location of hospitals are related to WPV and that regional or tertiary hospitals are particularly associated with WPV (26). Thailand is one country with universal health coverage (UHC), which has covered all Thai citizens through 3 public health insurance schemes since 2002 (27). There is a high demand for public tertiary hospital services in developing countries (28). At the same time, there is a high prevalence of violence at tertiary hospitals $(8,29)$. However, there is a lack of evidence on WPV at tertiary hospitals in Thailand. This study focuses on all healthcare workers in excellent public centers in Thailand. Furthermore, healthcare workers who work at government or large hospitals tend to experience more violence $(25,30-32)$.

Our study aims to assess the prevalence of, perpetrators of, and associated risk factors for WPV against healthcare workers in tertiary hospitals in Thailand. It examines healthcare workers' reports of rates of violence and investigates WPV. This research is an important step in exploring the current situation of workplace violence against all healthcare workers. The findings can inform the improvement of appropriate interventions, strategies, and policies related to violence against healthcare workers at tertiary hospitals in Thailand.

\section{Methods}

\section{Aims}

This study aims to survey the prevalence of, context of, and factors associated with violence against healthcare workers in excellent tertiary hospitals in Thailand.

\section{Study setting}

To select the study areas, simple random sampling was conducted, with two of ten excellent public tertiary centers selected. The selected centers had to be under different ministries with no duplicates. Seven of the ten centers are in Bangkok (70\%) (33). The ten centers include 4 hospitals of the Thailand Ministry of Higher Education, Science, Research and Innovation (MHESRI); 2 centers of the Thailand Ministry of Public Health (MPH); 2 centers of the Ministry of Defense; and 2 others (34). Additionally, the centers are equipped with sufficient professional medical 
expertise to treat a large number of patients from around the country under two very different structural schemes. One of the selected hospitals was under the MHESRI, and the other was under the MPH.

\section{Study design}

This was a mixed-method study. A retrospective cross-sectional design was adopted. Data were collected between July 2018 and March 2019 . To determine the sample size in this research, a calculation based on the event per variable (EPV) was used. The calculation advised 10 or more EPVs according to logistic regression (35) to assure the adequacy of the sample size in this research. We used $10 \%$ or more workers as the sample to account for missing data. The sample was randomly selected from each hospital and every unit. Random sampling was based on the size population of each setting. In the next step, the researcher used systematic random sampling to select the qualified individuals from every department in the two centers. Every fifth individual, such as 1,5,10...n, was selected. The process was repeated through all the departments in each center until the sample size calculated in the second step was reached. The inclusion criteria comprised being a healthcare worker, working at one of two tertiary healthcare centers in Thailand, possessing at least 12 months of tertiary hospital experience, being currently employed, being aged 20 years or above, and not being on vacation or leave. In addition, for the qualitative method, 30 participants were selected from the entire sample to provide in-depth information. To select the participants for the qualitative component, purposive sampling was conducted to include at least 15 healthcare workers from each hospital. The participants' willingness to participate and the convenience of participation for them as well as research ethics were prioritized.

\section{Materials}

\section{Quantitative instrument.}

Our study on WPV adopted the following definition of violence formulated by a WHO working group in 1996: "the intentional act of physical force or power, threatened or actual, against oneself, another person, or against a group or community" that is associated with working or any situation that happens in the workplace(36). Such violence results in degradation, deprivation, maldevelopment, and physical and psychological outcomes. In particular, psychological violence includes verbal abuse, bullying, racial harassment, and sexual harassment (36). The questionnaire was adapted from a questionnaire used in a previous study of a tertiary hospital in Thailand (37), and collaboratively by four international organizations (38); this questionnaire has often been used to survey violence at hospitals worldwide. The original English version of the questionnaire was divided into five parts. The Thai version was used in a recent international study that was conducted in Thailand in 2005 (37). It was found to have a content validity index of 0.93 for the total scale and of 0.85 for perception of violence. For our quantitative component, we used only two parts of the questionnaire: 1.) personal and workplace data and 2.) prevalence and context of WPV, such as physical violence and psychological violence (verbal abuse, bullying, sexual harassment, and racial harassment), including the characteristics of the perpetrator, reporting rate, and investigation experience of any type of WPV. Yes or no responses were used for most of the questions. The adapted questionnaire was then pilot tested with 30 participants from the same target population. Moreover, the researchers conducted two pilot tests of the questionnaire. The first was before submission to each research ethics committee. The second was after all recommendations and revisions were made in accordance with the ethics committees' consensus to suit both hospital contexts. After approval had been received from all committees is complete, the researchers collected the data following the schedule.

Qualitative instrument. A semistructuredinterview guide was developed and divided into five major categories based on the ecological model and the study objective.

\section{Data collection}

This study was approved by two ethics committees in 2017 and 2018. Next, in January 2018, the researcher approached hospital directors from 2 tertiary hospitals to ask for permission to enter the centers to conduct the research. Then, approval was sought from the supervisors or head of each unit by following the hierarchy of the organization and then, finally, consent was sought from the participants at mid-year. Data were collected between July 2018 and March 2019 using a survey questionnaire that was administered through a tablet. For the 30 participants who also participated in the qualitative study, the participants were informed of the research objectives, the potential harms and benefits of study participation and that the survey was confidential and voluntary. After informed consent was obtained, the author conducted an intervieweradministered survey in the Thai language using a tablet.

\section{Statistical analysis}

The analysis in this research was conducted in two phases. First, quantitative data analysis was performed by calculating the frequencies and percentages to quantify the types of violence according to demographic and workplace characteristics. The chi-square test was performed to assess the association between characteristics of independent factors and violence. Only variables with statistical significance ( $p \leq 0.05$ ) in the univariate analyses were analyzed in the multivariable logistic regression. The researchers used multivariable analysis to identify the independent variables related to the probability of healthcare workers experiencing violence in the workplace. Factors associated with the risk for 
hospital violence in Thailand are reported with 95\% confidence intervals (Cls). Statistical significance was determined as $\mathrm{p}<0.05$. Finally, qualitative data were analyzed using thematic analysis.

\section{Results}

\section{Characteristics of the participants and the workplace}

All 220 invited healthcare workers participated in this study, and the response rate was 100\%. Of these, 188 were women (85.5\%). Most participants (29.1\%) were 30-39 years old, and the average age was 38.54 years. The participants' incomes were between 25,000 and 50,000 baht per month, and their average income was 32,347 baht per month. Violence was most commonly observed in the outpatient department (OPD) (55.9\%). Violence most often occurred through direct interaction/contact with patients (89.1\%). [Table 1].

\section{Prevalence of violence against healthcare workers}

Overall, more than half (63.6\%) of the participants had experienced workplace violence over the 12-month period. Most participants were victims of verbal abuse (56.4\%), followed by physical violence (24.1\%), bullying (16.4\%), sexual harassment (4.1\%), and racial harassment (3.6\%) [Table 2].

\section{Characteristics of the perpetrators}

The participants described the gender of perpetrators of physical (60.4\%) and psychological violence (45.2\%) as both male and female. The most common perpetrators of physical violence (83.0\%) and psychological violence $(57.3 \%)$ were clients/patients. Regarding age, the perpetrators of all types of WPV were mostly older than the respondents [Table 3].

\section{Management of the participants and the investigation process}

Few participants $(\mathrm{N}=140,1.4 \%)$ indicated that they reported violent incidents every time. Most participants $(\mathrm{N}=140,57.9 \%)$ stated that they did not know about the investigation process from first-hand experience [Table 4].

\section{Associated factors of WPV}

First, the researchers compared the variables at the individual and organizational levels for the participants to identify trends in violence at the workplace. The relations among the variables were examined. Then, only the variables that had statistical significance $(P \leq 0.05)$ in the univariate analysis were selected [Table 1].Furthermore, the variables were entered one by one into the binary logistic model. Ultimately, 6 variables were assessed: gender, age, income, working experience, working in the OPD, and direct interaction/contact with patients. This analysis revealed that three factors, i.e., gender, working in the OPD, and direct interaction/contact with clients, had statistically significant relationships with violence at work [Table 5]. In the definite multivariate logistic regression model, three variables, i.e., male gender, working in the OPD, and direct interaction/contact with patients/clients, appeared to be significantly associated with WPV. It was found that men had a 4.28 times greater chance of having experienced violence than women. In terms of the work characteristics, healthcare workers in the OPD were 2.55 times more likely to experience violence than those in other departments, and those working with direct interaction/contact with patients/clients were 3.12 times more likely to encounter violence [Table 5].

Interviews were conducted with 30 healthcare staff regarding the WPV they experienced. From their narratives, five major themes were identified. In presenting the findings, quotes were used to manifest participants' voices.

\section{Individual level and WPV}

Several participant reflections focused on the issue of gender. First, many participants believed masculinity is a protective factor, compared to femininity, of workplace violence. From their perspective, women have more specific traits that relate to workplace violence than men. This was reflected in Miw's response about how she received abuse from her coworkers. "Men don't pay much attention to details as women do. Women are picky and can see a trifle as a problem or interpret it as something else. To ignore it and not see it as a problem is more difficult for women to do. Men see the big picture. Women have a detail-oriented view. So, men should be the leader too" (nurse, female, 42). Some women suffered abuse based on patriarchal idealism. The following is the voice of Wawa, who is a young professional who was bullied. She said, "The gender that causes violence the most is older males. It happens in the hospital on Facebook or LINE group chat. But most of it happens in the staff room during our break. The conflicts come from the fact that he worked here before me and has higher seniority yet a lower degree, while I'm a younger woman with a bachelor's degree who got promoted to be his supervisor. He might get upset, and that's where the conflicts arise"(Orthotist, female, 26). Finally, some participants saw the two genders as equally likely to victimize or perpetrate WPV. Few participants presented this experience. Buay is a female pharmacist who said, "Any genders can do it; working at the hospital requires professional expertise" (pharmacist, female, 34). Anothernurse assistant, who everyone calls I Big or Pee Bum [Fatty/Fatso/Chubby Boy], said, "Everyone has one brain, two hands and two legs. 
For physical strength, now some women are even a boxer or weightlifter. I think women are more eloquent than men. So, they can mediate in violent situations, and men can help back up. To put men in the front role is stupid. People back then often thought that women could not argue with men, but some women these days are smarter than men. I don't take gender into consideration but their action. (Pee Bum, a nurse assistant, male, 30). However, most of their reflections were from their perspectives as victims.

\section{Intergenerational gap among healthcare workers and WPV}

The qualitative data showed that the intergenerational gap among healthcare workers could result in WPV. This issue is divided into two parts. The first part considers the perspective of older persons. An example is the experience of Mai, an older female nurse who indicated that usually, her abuser is a young worker. She said, "One of the problems is to work with young people. They work well and smart, especially with IT. They learned with a new curriculum in the child center. They probably think everything revolves around them. So, the supervisor often sarcastically says that I'm already old as a dinosaur and do not learn to improve myself. I was disheartened and ashamed" (nurse, female, 55). The problem was found to be caused by work that changed the manner of interation with coworkers. Suree, a senior nurse from the heart center, said, "If I look back in history, nurses helped each other. Now, some young nurses work fast but not meticulously. They're good at technology though. Witty but thoughtless. If they get angry with someone, they ignore doing their job. They are passive-aggressive and neglect to help colleagues do our job; they use sarcasm, gibberish, and usually post bad things on Facebook. These affect our workload, and unsatisfactory to many of our clients (nurse, female, 47). On the other hand, young healthcare workers voiced opposite ideas. Several younger healthcare workers reflected that they were bullied by older staff, such as in the participants' reflections below. Yin is a young nurse who said, "We grew up in different era. Old people have a fixed mindset that is hard to change. When we do things like this, they'll say no, saying that the system doesn't allow for it, and we must do like that. But we see it doesn't work. Sometimes I choose to ignore it" (nurse, female, 25). Pam is a young nurse assistant who said, "Some are open-minded, but some are very narrow-minded and outdated. They're old as a dinosaur-hard to work with. So, we just work our own way" (nurse assistant, female, 31). The generational differences among workers was affected by the work manner, system, and their relationships at the workplace.

\section{Organizational level and WPV}

Our qualitative study found that violence did not necessarily have to take place in isolated places or while the victims were working alone. In this study, the high-risk area was the front of the department or the counter, which was crowded with many people. A male nurse assistant, Pee Bum, reflected, "The outpatient department has many people coming to use the services; approximately 200-300 patients use our services per half day every morning. We have long hours from early morning until afternoon to evening. Everyone is tired and stressed from work. Hard work, fewer workers, and repeatedly answering the same questions [from patients]. I understand that some [workers] may be upset, while patients have to be patient, sick, and angry" (Pee Bum, nurse assistant, male, 30). Moreover, the outpatient and emergency departments were very high-risk areas. Cob is an emergency medical officer of the OPD emergency department who said, "I've worked in many departments. The most at-risk department is the emergency OPD. There're a lot of patients. But I had little time to talk with each of them, so misunderstanding easily happened. At the outpatient emergency department, there're a load of patients too, but I don't get to have time to interact with them-only focusing on my wok. I also used to work in the inpatient ward. The violence is different. The cases in the ward weren't loaded, but we had problems with patients' relatives and were likely to get complaints easily. But work pressure, fatigue, sleep deprivation and stress were lower"(emergency medical officer, male, 39). On the other hand, healthcare workers in some jobs spend a long time with the patient without any problems. This was reflected by Sai. She said, "I work in the operating room. Almost every case takes more than one hour to finish. But there's no violence because most of the patients areunconscious. If there really needs to be problems, it's from the doctors because we prepare the room for them. Some doctors have their own standards" (nurse, female, 51). San had a similar reflection. He is a male occupational therapist, and he said, "My job is to provide occupational therapy to patients. Most of my patients have chronic to severe illness. One patient takes almost an hour. That gives me much enough time to be with them, so there's no problem" (occupational therapist, male, 35).

Furthermore, our results revealed a lack of material resources, insufficient backup data systems, unsupported welfare, and insufficient human resources. For example, Ki is a staff member of the obstetric department who said, "Lack of officers in all positions. Not enough healthcare workers. We're requesting more officers. Some have quit because of the low pay and no government registration. Also, there is no recruitment for new IT guys either. The computers malfunctioned like this for three to four years. When it malfunctions, it takes half an hour to be normal, causing a delay in printing. We can't print the health scheme documents. It happens in every department, affecting us all. In other examination rooms, doctors might not use a computer. But for me, I have to record the patients' symptoms in the computer for the doctors or print the health scheme documents for them. Sometimes, all I can do is just wait while patients keep an eye on me with a question when it'll be done. When the computer malfunctions like that, I'll call a person in charge to fix it and yell it out that it malfunctions, so everyone knows why it's slow. But whether they'll understand it or not, I don't know. Clients are God, supervisors are boss, and men are leaders. The patient waits for a long time and curses me in front of the counter. If I explain, it might be seen as controversial. There is nothing more I can do" (customer service officer, female, 39). 
The qualitative study found that violence in hospitals was based on the organizational structure. This hierarchy and power structure in the workplace influenced the occurrence of direct violence and indirect violence. This was reflected by some of the respondents. Jew, an assistant nurse of the eye center, said: "I'm just an assistant. I can't talk much. I take an order and follow it. No one complains, and it's the best" (nurse assistant, female, 29). As PeeBum said, "I'm not sure how long I'll work here. We're not doctors. Nobody respects us (laughs). We are good people who no one cares about" (nurse assistant, male, 30). The superior power of service users and patient satisfaction are key goals of working even in the most awkward and uncomfortable situations. An example is the experience of Ki. She said, " $A$ healthcare worker's job is to take care of the patients. Their satisfaction is the most important. If they are not satisfied, we can get complained about or scolded. In particular, aunties and wifies are less patient and easily irritated. If they've entered menopause, that's even worse. When they berate us, we can't do anything but have a service mindset"(customer service officer, female, 39). Furthermore, a relationship system in which two persons have unequal social status can lead to vertical violence because the leader and subordinate will always have unequal status. Some of the participants were negatively affected. For example, Samorn said, "I used to have a problem with my coworker. I reported it to the supervisor. But that coworker had a good relationship with their supervisors. So, I was the one who was ordered to relocate. I didn't want to have any further problems. When it was over, I moved to become a supervisor at another small department. It's better" (nurse, female, 55). Kwan's narrative was similar. Kwan was unsupervised. In her reflection, she said, "I was once assigned to be a supervisor in one department, but I couldn't put up with the pressure. So, I moved back to the old department. The higher you go, the harder you fall. If you're not strong enough or don't have enough people to back you up, it's hard to stay there. You'll become stressed and fall ill.It was too much for me, so I got back to work at the old department. No position but happy" (A nurse, female, 47). Violence can have a negative effect on physical, mental, emotional, professional, and professional growth in many ways.

\section{External organizational level and WPV}

We found that policy changes by external organizations could affect the participants' work. For example, after private hospitals cancelled the treatment service for patients on the social security scheme, many more patients came for service at government hospitals, leading to more chances of violence. Problems with the operating system and the number of patients are related to change factors of external organizations. For example, Ink is a pharmacist who said, "Yesterday, the patients had to wait for three hours because there're about 200 patients here. Many private hospitals cancelled services for patients on the social security scheme. So, a lot more patients came here for the service. Before this, only Tuesday would be crammed with about 200 patients, but these days, it's every single day. Greater workload and more violence" (pharmacist, female, 34). Additionally, some policies as reported by the participants caused them to feel unfairly treated, as they lost their rights to the changes that happened. Several participants suffered from policy changes. Sam is one healthcare worker whose welfare suffered. He said, "In my case, my work was affected by the change from a permanent secretary. I started working here as a temporary government employee and had worked for six years since. There was a law saying that if a person was appointed a civil servant, he or she could carry over their years of a track record as government employees to skip ranks without starting from zero. However, the new policy by the new permanent secretary imposed the new position by changing the position of a temporary government employee to the ministry employee, which was unknown and legally unclear to the Office of the Civil Service Commission. And when the law didn't include that new position, my six years of track record were gone" (occupational therapist, male, 35).

\section{Societal level and WPV}

Several respondents expressed violent events as follows. Ki is a customer service officer. She said, "People in Thai society today think that we're hired by the taxpayer's money, so we have to make it worth it even though we pay taxes too (laughs). In the past, patients respected us more, but these days, they have changed and seen us as service providers. Some even threaten us that they'll file a complaint. They stare at us, cross their arms, frown, or yell at the counter. They are God."(customer service officer, female, 47). The user's understanding of the service provider does not match the actual role and authority of the healthcare workers in the context of the organization, resulting in complaints. Suree described such an event. She said, "Society thinks that nurses can provide the treatment and prescribe the medicines, but in fact, we only follow the doctor's orders. Anyway, some treatment has a process, like you have to wait for four, six or 24 hours. Each profession has its own scope and limitation of work and roles, but people don't understand and want it to be as they want"(nurse, female, 47). Moreover, some healthcare workers reported bullying from coworkers, such as insults, scolding and sarcasm on social media. For example, Nuch, a psychologist, said, "After the conflict, she posted a picture of a foot on Facebook with a caption related to what happened, a dirty word, and I know it's about me" (clinical psychologist, female, 52). On the other hand, several occupations have developed increased work authority. However, in Thai society, there are still some people who believe that healthcare workers' work is simple. One research participant felt this was degrading in their profession. One young pharmacist said, "The world has changed. People used to understand that a pharmacist's job was only to prepare medicines and dispense it but in fact, it's not. Especially these days, pharmacists have to do more than just dispense medicines. I studied a new curriculum that took six years to graduate. The old one took five years. But the patients see us as a medicine dispenser only"(pharmacist, male, 27). Finally, the goal of the work of healthcare workers in today's Thai society, customer satisfaction, is as important to the hospital as any other service work. A smile is a necessity at work. For example, one nurse said, "I have to be more aware these days. Patients have changed. They know that they can file a complaint. I think it's more difficult to work now with people from different backgrounds. Many times, it makes me so bored that I don't want to do anything at all. But I have to be tough and put on the smiles. If anything can be let go, just do it"(nurse, female, 47). 


\section{Discussion}

Workplace violence among healthcare workers in Thailand is common. Our study found a prevalence of $63.6 \%$, with the most common type being verbal abuse. Specific attributes have been found to increase the risk of workers being targets of workplace violence in the healthcare setting, including gender, age, income, working experience, working in the OPD, and direct interaction/contact with patients $(15,16,39,40)$. Factors significantly associated with workplace violence included being male, having worked in an OPD, and having direct contact/interactions with clients.

\section{Prevalence and context of WPV}

Our study showed higher prevalences of all types of violence in the workplace than in the preceding study of a general hospital in southern Thailand in 2005 , which showed a prevalence of verbal abuse of $38.9 \%$, followed by a prevalence of physical violence of $3.1 \%$ and a prevalence of sexual harassment of $0.7 \%$ (37). Next, comparisons with other countries in Asia regarding the overall violence in tertiary hospitals within 12 months showed that the prevalence of violence experiences found in the current study of $63.6 \%$ was higher than that in mainland China, where the WPV prevalence was $56.4 \%$, as reported in a recent study (15). On the other hand, our finding seems lower than the overall rate of violence, $65.8 \%$, and verbal abuse, $64.9 \%$, in tertiary hospitals in China (41). Psychological violence was still higher than physical violence. Regarding the different types of WPV, a study in Hong Kong showed that only $1.1 \%$ of healthcare workers had experienced sexual violence (5). A study in northern Taiwan found the same prevalence of bullying as our study, i.e., 32.4\% (42). Although the issue of violence is of increasing interest due to the increasing prevalence of hospital violence, the reporting of rates of violence is insufficient.

\section{Associated factors and WPV}

This study found high risks of WPV. Regarding the first factor, the most violence was observed in the OPD. OPDs are available in almost all health services, such as emergency OPDs, cardiovascular OPDs, and obstetrics OPDs. All of them are crowded with people. Our qualitative study indicated that there were 100-600 people who sought services in the OPD in this department on a daily basis. Consistent with the findings from previous studies $(37,41)$. However, a prior inconsistent report indicated that outpatients of tertiary hospitals expressed the highest satisfaction with healthcare workers, especially doctors and nurses. However, the highest dissatisfaction was reported with health center sanitation and outpatients operations, particularly with long wait times, prediagnosis counters, and registration/payment officers (29). In terms of the second factor, direct physical contact could result in more violence. This relates to a previous study, when the staff was either preparing for or providing health services (43). This corresponded to the findings of a study in Hong Kong and China $(16,41,44)$. The third factor was the last factor of our logistics model. The gender of the participants relates to our qualitative result. Being male is one possible factor of violence in the workplace, consistent with previous studies in Thailand conducted $1-2$ decades ago $(37,45)$. A recent finding was similar to that of previous studies in China $(15,46)$. However, these findings contrasted with several studies $(3,47)$. This relates to our qualitative result, which could be explained by the fact that, according to gender roles, males were perceived to be stronger than females, and it was expected that they would be able to tolerate pain without complaints, according to a concept of masculinity. The gendered division of labor resulted in different gender roles. For example, men were viewed as leaders and a reasonable and strong gender who could protect women, while women were seen to be good at details and mediation, especially when verbal communication was required. These perceptions consequently influenced gender relations and/or power relations. To illustrate, men were chosen to be leaders but at the same time to perform violence-prone jobs. Although the female participants reported that they were well aware that if they chose men to be leaders, a male leader might not understand women and their jobs well, based on their experience, they still chose men to be leaders. However, if they saw a nominated woman with the same leadership skills, they would choose the woman. The participants also reported that although most supervisors at the hospitals were women, the executives were men. This could indicate that gender stereotypes had effects on gender equity, as they could prohibit female workers from reaching their highest career paths even though there was no such official restriction against women to have a high position in an organization. However, at the time of the research, the participants revealed that they thought that they had gender equity because women by then already had equal job opportunities as men and could further their education for their career path development. In addition, gender studies of male-dominated occupations found that men were given risky work (Stergiou-Kita et al., 2015).

On the other hand, the study identified characteristics of the perpetrators of WPV. The main source of violence, including both physical and verbal abuse, was patients, which is consistent with the findings of many studies $(18,37,48,49)$. Our finding of the characteristics of perpetrators was slightly different, as our results indicate that the main perpetrators of physical violence and verbal abuse could be either males or females, followed closely by female perpetrators of verbal abuse. Perpetrators were most likely to be older. For both physical and verbal abuse, this finding corresponded with a prior study on physical violence in Turkey (50). In addition, in our qualitative results, we found intergenerational conflict in the workplace. Intergenerational conflict was a dominant theme in our qualitative results. Intergenerational conflict related to differences in age, working experience, life experience, curriculum of study, etc., of any generation. However, this finding was confirmed by studies on intimate partner or domestic violence. Such violence tends to be disrupted over generations (51), and a previous study indicated that interpersonal conflict continues to be a reality in the nursing profession, and nurse educators, practicing nurses, and nursing students work to effect change and create a more cohesive culture. The findings have the potential to enhance generational

Page $7 / 15$ 
understanding and foster a more cohesive culture in clinical practice settings (52). Overall, the difference could be attributed to cultural differences. Finally, this study reveals a low rate of reporting of experienced violent incidents among the participants due to the desire to avoid consequent work problems. Additionally, no procedures were undertaken after the violence was performed to investigate its roots.

The recent exploration was similar to prior studies in many European and other countries $(39,53)$.

\section{Organizational, external organizational level and WPV}

Our qualitative study found that the structure of the management system under the supervising organization, which was considered the external organization, affected healthcare workers' promotion, salary and career paths. This was considered structural violence according to the findings of the qualitative study reporting the reflection of participants. The findings showed that any changes caused by external organizations, such as changes in political agencies, health policy of the relevant ministry, policy of private hospitals in the community, etc., could affect the progression of the careers of healthcare workers. This was consistent with the findings of a study in Thailand almost 20 years ago (45).

\section{Societal level and WPV}

This study found that some social expectations contrasted with the real working system and context in hospitals. It is obvious that macro factors, such as norms, cultures, values, beliefs, social expectations toward healthcare workers, professionality, service expectations, and customers' rights and taxpayers' rights, have both direct and indirect impacts on violence in hospitals. First, the qualitative study also found that clients' social expectations prevailed in healthcare workers' job roles, which allowed violence to exist at hospitals. Thai hospitals are free for all, and if they are sick, people can access rights as patients. More important than the right of the patient is the right of the taxpayer. The patient's threatening claims made the participants feel oppressed. Additionally, different classes, such as the service class and the customer, have distinct power. Furthermore, the client is unperceptive of the actual role and authority of the healthcare workers in context. In addition, the world and technology are changing. Expressions change and become more approachable; when there is a problem, people can easily vent about them on social media. Violence on social media is easy and fast. Since then, professional development has progressed, but the stigmatized maldevelopment of Thai society has remained the same, as exemplified by the narratives of the participants in our results. Ultimately, the immediate solution is to smile at the customer. These findings were similar to those of a study in Thailand (45). Moreover, gender-based violence, power in the organization, and social influence were related. The study found that this type of violence could penetrate deep into many levels, even to an attitude of the participants toward genders. The qualitative data also revealed that even though the hospital system had been improved, it was still partially dominated by the patriarchy. Additionally, despite the hierarchy in the hospitals, where the healthcare workers were under the control of the hospital management committee and the committee was under the control of the relevant ministry, capitalism also came into play and placed the first priority on the satisfaction and safety of the hospital clients or patients, as in a commonly spoken phrase "clients are God, supervisors are boss, and men are leaders." This shows that societal factors, especially culture in Thai society, influence and interact on hospital violence through ego, instinct, core beliefs, job conditions, and the structure of the organization. Furthermore, organizations and external organizations, including society and the world, change (54-57). This study has some limitations. First, this was a cross-sectional study of only two of ten excellent public centers in Thailand. The findings may not be generalizable to all levels of hospitals in Thailand. Nevertheless, both hospitals are considered leaders in medical treatments, medical education, and clinical research among Thai hospital systems. Second, due to the vulnerability of the topic, the researcher took a long period of time and navigated many hierarchies to obtain permission to enter the areas, addressing fears of negative consequences of participation and waiting for permission from all units and persons. We addressed these issues by going in-person to talk and explain the purpose with everyone individually and sincerely. Third, we aimed to intensify the rigor and reduce the bias due to data collection on this sensitive topic and overcome the limitation of asking participants to recall over the past 12 months. Then, the researchers collected data by reading each research participant each question one on one, used the international questionnaire that was translated to Thai in a prior international publication, and conducted in-depth interviews through qualitative processes. Last, the quantitative sample was based on the number of independent variables that would be used in the logistic models, including no funding or time constraints. However, the study was a mixed method study, with a qualitative sample of 30 people.

\section{Conclusion}

After almost twenty years since the last study on this topic, this study provides evidence of the up-to-date prevalence of WPV at tertiary hospitals in Thailand. The study revealed the high prevalence of WPV among all healthcare workers. There are many types of violence in the workplace. Several factors could influence WPV, such as being a man, working in the OPD, having poor working systems, and working with many patients/clients. The results could contribute to the advancement of policies and measurements to prevent and resolve WPV at large and complex hospitals. Moreover, the results could also contribute to the development of longitudinal studies in the future and establish selfadministrative reporting without negative consequences, including programs for intergenerational conflicts and zero-tolerance policies for all healthcare workers.

\section{Declarations}


Our research was reviewed and approved by the Human Research Ethics Committee of the Ministry of Public Health Rajavithi Hospital (Document No. 117/2560), and by the Human Research Ethics Committee of the Faculty of Medicine at Ramathibodi Hospital, Mahidol University (Document No. MURA 2560/120). Informed consent was obtained from all participants. All methods were carried out in accordance with relevant guidelines and regulations of the Declaration of Helsinki.

\section{Consent for publication}

Not applicable

\section{Availability of data and materials}

The datasets that were used and analyzed in the current research are not publicly available due to the measures stated in the informed consent form taken to protect the rights of the participants. However, the dataset is accessible from the corresponding author upon reasonable request.

\section{Competing interests}

We declare that we have no competing interests.

\section{Funding}

Not applicable

Author contributions: Conceptualization: Sophida Kueanongkhun, Siriwan Grisurapong, Kitirat Techatraisak, Thomas Guadamuz; Data curation: Sophida Kueanongkhun; Formal analysis: Sophida Kueanongkhun; Funding acquisition: Sophida Kueanongkhun; Methodology: Sophida Kueanongkhun, Thomas Guadamuz; Project administration: Sophida Kueanongkhun; Supervision: Thomas E. Guadamuz; Writing, original draft: Sophida Kueanongkhun; Writing, review \& editing: Thomas E. Guadamuz.

\section{Acknowledgments}

The authors thank all the participants, their friends, their parents, their teachers, and the hospitals for their support of this research.

\section{References}

1. Hills D, Lam L, Hills S. Workplace aggression experiences and responses of Victorian nurses, midwives and care personnel. Collegian. 2018 Dec;25(6):575-82.

2. Johansen IH, Baste V, Rosta J, Aasland OG, Morken T. Changes in prevalence of workplace violence against doctors in all medical specialties in Norway between 1993 and 2014: a repeated cross-sectional survey. BMJ Open. 2017 Aug;7(8):e017757.

3. Schablon A, Wendeler D, Kozak A, Nienhaus A, Steinke S. Prevalence and Consequences of Aggression and Violence towards Nursing and Care Staff in Germany-A Survey. IJERPH. 2018 Jun 15;15(6):1274.

4. Vento S, Cainelli F, Vallone A. Violence Against Healthcare Workers: A Worldwide Phenomenon With Serious Consequences. Front Public Health. 2020 Sep 18;8:570459.

5. Cheung T, Yip PSF. Workplace violence towards nurses in Hong Kong: prevalence and correlates. BMC Public Health. 2017 Dec;17(1):196.

6. World Health Organization, editor. World report on violence and health: summary. Geneva; 2002. 44 p.

7. Zhao S, Qu L, Liu H, Gao L, Jiao M, Liu J, et al. Coping with Workplace Violence against General Practitioners and Nurses in Heilongjiang Province, China: Social Supports and Prevention Strategies. Fischer G, editor. PLoS ONE. 2016 Jun 21;11(6):e0157897.

8. Duan X, Ni X, Shi L, Zhang L, Ye Y, Mu H, et al. The impact of workplace violence on job satisfaction, job burnout, and turnover intention: the mediating role of social support. Health Qual Life Outcomes. 2019 Dec;17(1):93.

9. Chambers CNL, Frampton CMA, McKee M, Barclay M. 'It feels like being trapped in an abusive relationship': bullying prevalence and consequences in the New Zealand senior medical workforce: a cross-sectional study. BMJ Open. 2018 Mar;8(3):e020158.

10. Vittorio di Martino. Relationship of work stress and workplace violence in the health sector. 2003;38. 
11. Zhang Y, Punnett L, McEnany GP, Gore R. Contributing influences of work environment on sleep quantity and quality of nursing assistants in long-term care facilities: A cross-sectional study. Geriatric Nursing. 2016 Jan;37(1):13-8.

12. Galtung J. Violence, Peace, and Peace Research. Journal of Peace Research. 1969 Sep;6(3):167-91.

13. Johan Galtung. Cultural Violence. Journal of Peace Research. 1990;Aug., 1990(27):291-305.

14. Krug EG, World Health Organization, editors. World report on violence and health. Geneva; 2002. 346 p.

15. Tian Y, Yue Y, Wang J, Luo T, Li Y, Zhou J. Workplace violence against hospital healthcare workers in China: a national WeChat-based survey. BMC Public Health. 2020 Dec;20(1):582.

16. Cheung T, Yip PSF. Workplace violence towards nurses in Hong Kong: prevalence and correlates. BMC Public Health. 2017 Dec;17(1):196.

17. Niu S-F, Kuo S-F, Tsai H-T, Kao C-C, Traynor V, Chou K-R. Prevalence of workplace violent episodes experienced by nurses in acute psychiatric settings. Tye M, editor. PLoS ONE. 2019 Jan 24;14(1):e0211183.

18. Yoo HJ, Suh EE, Lee SH, Hwang JH, Kwon JH. Experience of Violence from the Clients and Coping Methods Among Intensive Care Unit Nurses Working in a Hospital in South Korea. Asian Nursing Research. 2018 Jun;12(2):77-85.

19. Siriwan Grisurapong. https://www.oudconsultancy.nl/Resources/Proceedings_3rd_Workplace_Violence_2012.pdf. In Vancouver, Canada; 2012 [cited 2016 May 2]. p. 71-3. Available from: https://www.oudconsultancy.nl/Resources/Proceedings_3rd_Workplace_Violence_2012.pdf

20. Kasai Y, Mizuno T, Sakakibara T, Thu S, Kyaw TA, Htun KA. A survey of workplace violence against physicians in the hospitals, Myanmar. BMC Res Notes. 2018 Dec;11(1):133.

21. Coskun Cenk S. An analysis of the exposure to violence and burnout levels of ambulance staff. Turkish Journal of Emergency Medicine. 2019 Jan;19(1):21-5.

22. Dehghan-Chaloshtari S, Ghodousi A. Factors and Characteristics of Workplace Violence Against Nurses: A Study in Iran. J Interpers Violence. 2017 Jan 9;088626051668317.

23. Hsieh H-F, Chen Y-M, Wang H-H, Chang S-C, Ma S-C. Association among components of resilience and workplace violence-related depression among emergency department nurses in Taiwan: a cross-sectional study. Journal of Clinical Nursing [Internet]. 2016 Jun [cited 2016 Jun 26]; Available from: http://doi.wiley.com/10.1111/jocn.13309

24. Findorff MJ. Risk factors for work related violence in a health care organization. Injury Prevention. 2004 Oct 1;10(5):296-302.

25. Liu H, Zhao S, Jiao M, Wang J, Peters D, Qiao H, et al. Extent, Nature, and Risk Factors of Workplace Violence in Public Tertiary Hospitals in China: A Cross-Sectional Survey. IJERPH. 2015 Jun 16;12(6):6801-17.

26. Boafo IM, Hancock P. Workplace Violence Against Nurses. SAGE Open. 2017;2017:9.

27. Tangcharoensathien V, Suphanchaimat R, Thammatacharee N, Patcharanarumol W. Thailand's Universal Health Coverage Scheme. Economic and Political Weekly [Internet]. 2012 Feb 25 [cited 2020 Jan 25];47. Available from: chromeextension://gphandlahdpffmccakmbngmbjnjiiahp/https://extranet.who.int/kobe_centre/sites/default/files/pdf/2_8_Case\%20study_Thailand.pdf 28. Subburaman G-BB, Hariharan L, Ravilla TD, Ravilla RD, Kempen JH. Demand for Tertiary Eye Care Services in Developing Countries. American Journal of Ophthalmology. 2015 Oct;160(4):619-627.e1.

29. Li Y, Gong W, Kong X, Mueller O, Lu G. Factors Associated with Outpatient Satisfaction in Tertiary Hospitals in China: A Systematic Review. IJERPH. 2020 Sep 27;17(19):7070.

30. Pinar T, Acikel C, Pinar G, Karabulut E, Saygun M, Bariskin E, et al. Workplace Violence in the Health Sector in Turkey: A National Study. J Interpers Violence [Internet]. 2015 [cited 2019 Sep 5];32(15):2345-65. Available from:

http://journals.sagepub.com/doi/10.1177/0886260515591976

31. Yan T, Li S, Pan G, Qu B. Perceived Risk of Violence in Various Hospital Levels and De- partments in Urban and Rural China. $2016 ; 3$.

32. Zeng HJ, Zhou GY, Yan HH, Yang XH, Jin HM. Chinese nurses are at high risk for suicide: A review of nurses suicide in China $2007-2016$.

Archives of Psychiatric Nursing. 2018 Dec;32(6):896-900. 
33. Strategy and Planning Division.

http://gishealth.moph.go.th/healthmap/gmap.php\#result

34. Strategy and Planning Division ,Office of the Permanent Secretary, Ministry of Public Health. Thai Health Coding Center, National Center for Code Standards and Health Information. [Internet]. 2018 [cited 2018 Feb 15]. Available from: http://203.157.10.8/hcode/p_export.php

35. Peduzzi P, Concato J, Kemper E, Holford TR, Feinstein AR. A simulation study of the number of events per variable in logistic regression analysis. Journal of Clinical Epidemiology. 1996 Dec;49(12):1373-9.

36. Krug EG, Mercy JA, Dahlberg LL, Zwi AB. The world report on violence and health. The Lancet. 2002 Oct;360(9339):1083-8.

37. Kamchuchat C, Chongsuvivatwong V, Oncheunjit S, Yip TW, Sangthong R. Workplace Violence Directed at Nursing Staff at a General Hospital in Southern Thailand. J Occup Health. 2008;50(2):201-7.

\section{Wiskow C. WORKPLACE VIOLENCE IN THE HEALTH SECTOR. 2003;14.}

39. Kitaneh M, Hamdan M. Workplace violence against physicians and nurses in Palestinian public hospitals: a cross-sectional study. BMC Health Serv Res. 2012 Dec;12(1):469.

40. Kristen E, Banuelos B, Urban D. Workplace Violence and Harassment of Low-Wage Workers. 2015;36:47.

41. Shi L, Zhang D, Zhou C, Yang L, Sun T, Hao T, et al. A cross-sectional study on the prevalence and associated risk factors for workplace violence against Chinese nurses. BMJ Open. 2017 Jun;7(6):e013105.

42. Obeidat RF, Qan'ir Y, Turaani $H$. The relationship between perceived competence and perceived workplace bullying among registered nurses: $A$ cross sectional survey. International Journal of Nursing Studies. 2018 Dec;88:71-8.

43. Cashmore AW, Indig D, Hampton SE, Hegney DG, Jalaludin BB. Workplace violence in a large correctional health service in New South Wales, Australia: a retrospective review of incident management records. BMC Health Serv Res. 2012 Dec;12(1):245.

44. Liu Y, Zhang M, Li R, Chen N, Huang Y, Lv Y, et al. Risk assessment of workplace violence towards health workers in a Chinese hospital: a cross-sectional study. BMJ Open. 2020 Dec;10(12):e042800.

45. Kasara Sripichyakan PT, Bungorn Supavititpatana. Workplace violence in the health sector; a case study in Thailand. 2003.

46. Lu L, Dong M, Wang S-B, Zhang L, Ng CH, Ungvari GS, et al. Prevalence of Workplace Violence Against Health-Care Professionals in China: A Comprehensive Meta-Analysis of Observational Surveys. Trauma, Violence, \& Abuse. 2018 May 27;152483801877442.

47. Ferri P, Silvestri M, Artoni C, Di Lorenzo R. Workplace violence in different settings and among various health professionals in an Italian general hospital: a cross-sectional study. PRBM. 2016 Sep;Volume 9:263-75.

48. Shafran-Tikva S, Chinitz D, Stern Z, Feder-Bubis P. Violence against physicians and nurses in a hospital: How does it happen? A mixedmethods study. Isr J Health Policy Res. 2017 Dec;6(1):59.

49. Yenealem DG, Woldegebriel MK, Olana AT, Mekonnen TH. Violence at work: determinants \& prevalence among health care workers, northwest Ethiopia: an institutional based cross sectional study. Ann of Occup and Environ Med. 2019 Dec;31(1):8.

50. Hamzaoglu N, Türk B. Prevalence of Physical and Verbal Violence Against Health Care Workers in Turkey. Int J Health Serv. 2019 Oct; $49(4): 844-61$.

51. Woollett N, Thomson K. Understanding the intergenerational transmission of violence. S Afr Med J. 2016 Nov 2;106(11):1068.

52. Foley V, Myrick F, Yonge O. Intergenerational conflict in nursing preceptorship. Nurse Education Today. 2013 Sep;33(9):1003-7.

53. Babiarczyk B, Turbiarz A, Tomagová M, Zeleníková R, Önler E, Sancho Cantus D. Reporting of workplace violence towards nurses in 5 European countries - a cross-sectional study. Int J Occup Med Environ Health. 2020 Apr 30;33(3):325-38.

54. Beck, A. T. Cognitive therapy and the emotional disorders. New York, NY: International Universities Press; 1976.

55. Beck, A. T. Depression: Causes and treatment. Philadelphia: University of Pennsylvania Press; 1967.

56. Rosa EM, Tudge J. Urie Bronfenbrenner's Theory of Human Development: Its Evolution From Ecology to Bioecology: The Evolution of Urie Bronfenbrenner's Theory. J Fam Theory Rev. 2013 Dec;5(4):243-58.

Page 11/15 
57. Ashiabi GS, O’Neal KK. Child Social Development in Context: An Examination of Some Propositions in Bronfenbrenner's Bioecological Theory. SAGE Open. 2015 Jun 19;5(2):215824401559084.

\section{Tables}

Table 1 characteristics of participants, work and workplace $(\mathrm{N}=220)$ 


\begin{tabular}{|c|c|c|}
\hline Variables & N (\%) & $\chi^{2}$ \\
\hline Gender & & $0.178^{* *}$ \\
\hline Female & 188 (85.5) & \\
\hline Male & $32(14.5)$ & \\
\hline Age (years) & & $-0.141^{*}$ \\
\hline $20-29$ & $56(25.5)$ & \\
\hline $30-39$ & $64(29.1)$ & \\
\hline $40-49$ & $52(23.6)$ & \\
\hline$\geq 50$ & $48(21.8)$ & \\
\hline Level of education & & 0.026 \\
\hline Secondary school and below & $15(6.8)$ & \\
\hline Vocational certificate & $40(18.2)$ & \\
\hline Bachelor's degree & $121(55.0)$ & \\
\hline Above bachelor's degree & $38(17.3)$ & \\
\hline Income (baht) & & $-0.187 * *$ \\
\hline$<25,000$ & $57(25.9)$ & \\
\hline $25,000-50,000$ & $121(55.0)$ & \\
\hline$>50,000$ & $42(19.1)$ & \\
\hline Occupation & & -0.005 \\
\hline Nurse & $101(45.9)$ & \\
\hline Professional assistant & $72(32.7)$ & \\
\hline Other & $47(21.4)$ & \\
\hline Work in shifts (multiple answers are possible) & & 0.094 \\
\hline Work hours & $125(56.8)$ & \\
\hline Shifts & $95(43.2)$ & \\
\hline Both & $27(12.3)$ & \\
\hline Working experience (years) & & $-0.148^{*}$ \\
\hline $0-10$ & 96 (43.6) & \\
\hline$>10-20$ & $45(20.5)$ & \\
\hline$>20-30$ & $44(20.0)$ & \\
\hline$>30$ & $35(15.9)$ & \\
\hline Exposure to outpatient department (working department) & & $0.204^{* *}$ \\
\hline Yes & $123(55.9)$ & \\
\hline No & $97(44.1)$ & \\
\hline Direct interaction/contact with clients & & $0.160 *$ \\
\hline Yes & $196(89.1)$ & \\
\hline Affiliation Hospital & & 0.125 \\
\hline Hospital of MHESRI & $151(68.64)$ & \\
\hline Hospital of MPH & 69 (31.36) & \\
\hline
\end{tabular}

${ }^{1}$ Each item refers to yes/no response. 
Table 2 Frequency, percentage, and forms of violence experienced in a hospital within the past 12 months

\begin{tabular}{cr}
\hline Violence experienced in a hospital & $\mathrm{N}=220(\%)$ \\
\hline Overall violence & $140(63.6)$ \\
Verbal abuse & $124(56.4)$ \\
Physical violence & $53(24.1)$ \\
Bullying & $36(16.4)$ \\
Sexual harassment & $9(4.1)$ \\
Racial harassment & $8(3.6)$ \\
\hline
\end{tabular}

Note: Multiple answers are possible.

Table 3 The characteristics of perpetrators $(\mathrm{N}=220)$

\begin{tabular}{|c|c|c|c|c|}
\hline \multicolumn{2}{|l|}{$\begin{array}{c}\text { PV } \\
(\mathrm{N}=53)\end{array}$} & \multicolumn{2}{|c|}{$\begin{array}{c}\text { VA } \\
(\mathrm{N}=124)\end{array}$} & \\
\hline $\mathrm{F}$ & $\%$ & $\mathbf{F}$ & $\%$ & \\
\hline \multicolumn{5}{|l|}{ Gender of perpetrators } \\
\hline Male & 13 & 24.5 & 14 & 11.3 \\
\hline Female & 8 & 15.1 & 54 & 43.5 \\
\hline Both & 32 & 60.4 & 56 & 45.2 \\
\hline \multicolumn{5}{|c|}{ Status of perpetrators (Multiple answers are possible.) } \\
\hline Clients/patients & 44 & 83.0 & 71 & 57.3 \\
\hline Coworkers & 9 & 17.0 & 63 & 50.8 \\
\hline Managers/Supervisors & 2 & 3.8 & 20 & 16.1 \\
\hline Outsiders / strangers & 1 & 1.9 & 1 & 0.8 \\
\hline \multicolumn{5}{|c|}{ Age of the perpetrator compared to the respondents (Multiple answers are possible.) } \\
\hline Older & 42 & 79.2 & 101 & 81.5 \\
\hline Younger & 17 & 32.1 & 54 & 43.5 \\
\hline same age as respondents & 6 & 11.3 & 23 & 18.5 \\
\hline
\end{tabular}

Table 4 The reporting and the investigation during and after the violence incidence at hospitals.

\begin{tabular}{lcccccc}
\hline Supportive system & $\begin{array}{c}\text { Violence } \\
(\mathbf{N}=\mathbf{1 4 0})\end{array}$ & $\begin{array}{c}\text { Physical violence } \\
(\mathbf{N}=53)\end{array}$ & $\begin{array}{c}\text { Psychological Violence } \\
(\mathbf{N = 1 2 6})\end{array}$ \\
\cline { 2 - 7 } & $\mathbf{n}$ & $\%$ & $\mathbf{n}$ & $\%$ & $\mathbf{n}$ & $\%$ \\
\hline Report behaviours & & & & & & \\
\hline None & 68 & 48.6 & 22 & 41.5 & 66 & 52.4 \\
\hline Sometimes & 70 & 50.0 & 31 & 58.5 & 58 & 46 \\
\hline Every time & 2 & 1.4 & 0 & 0 & 2 & 1.6 \\
\hline investigate & & & & & & \\
None & 81 & 57.9 & 22 & 41.5 & 83 & 65.9 \\
\hline Sometimes & 37 & 26.4 & 16 & 30.2 & 33 & 26.2 \\
\hline Every time & 22 & 15.7 & 15 & 28.3 & 10 & 7.9 \\
\hline
\end{tabular}

Table 5 Risk factors associated with the violence at tertiary hospital in Thailand $(\mathrm{N}=220)$ 


\begin{tabular}{lrrc}
\hline Variables & Sig. & N (\%) & Risk of hospital violence Exp(B) $(95 \%$ CI $)$ \\
\hline Gender & & & \\
Male & 0.007 & $32(14.5)$ & 4.28(1.50-12.19) ** \\
\hline Female & & $188(85.5)$ & Reference \\
\hline Department & & & $2.55(1.42-4.58) * *$ \\
\hline OPD & 0.002 & $123(55.9)$ & Reference \\
\hline No & & $97(44.1)$ & $3.12(1.25-7.73) *$
\end{tabular}

Note: ${ }^{*} \mathrm{p} \leq 0.05 ;{ }^{* *} \mathrm{p}<0.01 ; * * * \mathrm{p}<0.001$ 